\section{Anaphylaxis to Cefazolin in the Second Trimester: A Case Report}

\section{Abstract}

Anaphylactic reactions during pregnancy are uncommon and can trigger maternal hypotension. These hemodynamic changes increase both maternal and fetal morbidity and mortality as emergent cesarean delivery is often necessary due to worsening fetal status. Only a handful of case reports describe perioperative and intraoperative management of anaphylaxis in pregnancy. We present a patient in her second trimester with twin-twin transfusion syndrome who experienced anaphylaxis to cefazolin prior to the start of a fetoscopic laser procedure for photocoagulation of pathological placental anastomoses.

Keywords: Anaphylaxis; Second trimester; Pregnancy; Cefazolin; Allergy

Received: March 24, 2020; Accepted: May 04, 2020; Published: May 08, 2020

\section{Key Highlights}

- Anaphylaxis in pregnancy carries a high risk of fetal morbidity and mortality.

- Immediate management is similar to that of non-pregnant women.

- Epinephrine is the first line supportive medication.

- A multidisciplinary approach is needed in the maternal resuscitation.

- There is no allergic cross reactivity between cefazolin and penicillin.

\section{Introduction}

Anaphylaxis is a rare complication during the second trimester of pregnancy. Like many diseases, pregnancy should not influence maternal treatment. Most reported cases of anaphylaxis in pregnancy occur around the time of delivery and fetal heart rate changes distress secondary to maternal hypotension often results in emergency delivery. We report the first case of maternal anaphylaxis occurring in the setting of laser photocoagulation for twin-twin transfusion syndrome (TTTS), and the third known case during the second trimester of pregnancy with good maternal and fetal outcomes [1,2]. This is a case of a woman with a monochorionic, diamniotic (MCDA) twin gestation in the second trimester of pregnancy who experienced anaphylaxis due to cefazolin administration prior to the start of fetoscopic laser surgery for TTTS. The patient provided written consent for the publication of the case.

\section{Daoud $\mathrm{BE}^{1 *}$, $\mathrm{He} \mathrm{L}^{2}$, Miller R${ }^{1}$, Nhan-Chang $\mathrm{CL}^{1}$ and Meng $\mathrm{ML}^{3}$}

1 Columbia University Medical Center, Department of Anesthesiology, New York, USA

2 Columbia University Medical Center, Department of Obstetrics and Gynecology, New York, USA

3 Duke University Medical Center, Department of Anesthesiology, Durham, USA

* Corresponding author: Daoud BE

\section{BD2369@columbia.edu}

Columbia University Medical Center, Department of Anesthesiology 622 West 168th Street New York, NY 10032, USA.

Tel: $212-342-2028$

Citation: Daoud BE, He L, Miller R, Chang CLN, Meng ML (2020) Anaphylaxis to Cefazolin in the Second Trimester: A Case Report. Gynecol Obstet Case Rep Vol.6 No.2:15

\section{Case Report}

Our patient is a 37-year-old otherwise healthy, G4P3 at 19 weeks 5 days gestational age with a MCDA twin pregnancy complicated by TTTS who presented for fetoscopic laser photocoagulation of pathological placental anastomoses. Baseline maternal heart rate was 113 beats per minute, blood pressure $90 / 59 \mathrm{mmHg}$, and oxygen saturation $98 \%$ on room air. Combined spinal epidural anesthesia technique was used (intrathecal doses: fentanyl $15 \mathrm{mcg}$ and hyperbaric bupivacaine $7.5 \mathrm{mg}$ ). Cefazolin $2 \mathrm{~g}$ infusion was initiated. Five minutes into the infusion (1g of cefazolin given) the patient experienced itching on the face and hives were noted. Diphenhydramine 50mg IV was given. Two minutes later, the patient experienced shortness of breath, with facial edema and wheezing was appreciated on auscultation. Dexamethasone $10 \mathrm{mg}$ IV and epinephrine $10 \mathrm{mcg}$ IV were given followed by an 
infusion of epinephrine $0.5 \mathrm{mcg} / \mathrm{min}$. Heart rate remained at baseline of 120 beats per minute, blood pressure was 105-125/50$60 \mathrm{mmHg}$ and oxygen saturation remained $98-100 \%$ on room air. Ultrasound assessment of fetal heart rates were adequate but the donor fetal heart was noted to be hypercontractile with an irregular rhythm during the first 10 minutes of recognition of the anaphylactic response and initiation of epinephrine. Vital signs were observed for 40 minutes after the antibiotic was dosed and since she remained stable on the epinephrine infusion. As the laser procedure was urgent, the decision was made to proceed with the procedure once the patient was stabilized. The 45-minute procedure was uneventful. The hives resolved by the end of the case.

Post-operatively, epinephrine was decreased to $0.25 \mathrm{mcg} / \mathrm{min}$ two hours after antibiotic dosing but the patient experienced recurrent shortness of breath, so the infusion was resumed at $0.5 \mathrm{mcg} / \mathrm{min}$ for 8 more hours. The epinephrine was then reduced to $0.25 \mathrm{mcg} / \mathrm{min}$ for another 4 hours. Other medications administered during recovery included famotidine $20 \mathrm{mg}$ IV, nalbuphine $5 \mathrm{mg} \mathrm{IV}$, diphenhydramine $50 \mathrm{mg} \mathrm{IV}$, and hydrocortisone $100 \mathrm{mg}$ IV. Postoperative tryptase levels were $<2.0 \mathrm{ug} / \mathrm{L}$. Epinephrine was ultimately discontinued, and the patient was observed overnight before being discharged home in the morning in stable condition.

\section{Discussion}

Anaphylaxis during pregnancy jeopardizes the life of the mother and fetus, as profound hypotension can result in maternal and fetal hypoperfusion and premature delivery that can be emergent. This is the first reported case of maternal anaphylaxis occurring in the setting of laser photocoagulation for twin-twin transfusion syndrome (TTTS). Anaphylaxis in the second trimester increases fetal morbidity. This is the third reported cases of anaphylaxis during the second trimester of pregnancy with good maternal and fetal outcomes (Tables 1 and 2) [1,2]. Compared to the general perioperative population in which neuromuscular blockers are the most common cause of anaphylaxis, antibiotics are the most common cause of anaphylaxis during pregnancy [3]. Other less common causes of anaphylaxis during pregnancy are listed in Tables $\mathbf{1}$ and $\mathbf{2}$. This patient was previously exposed to cefazolin during a laparoscopic cholecystectomy without any allergic reactions. Re-exposure to an allergen can precipitate anaphylaxis. This can be worsened in pregnancy with the postulated mechanism being an increased $\mathrm{TH} 2$ response, a known inducer of IgE synthesis [4].

Management of anaphylaxis in pregnant women should be similar to that of non-pregnant women with a few additional caveats (Figure 1) [5]. The first step is recognition of anaphylaxis and cessation of the triggering agent followed by airway and hemodynamic support, oxygen supplementation and fluid resuscitation. Anesthesiologists and obstetricians should be called to assist in the maternal resuscitation. Epinephrine is the vasopressor of choice in anaphylaxis because it provides bronchodilation, decreases upper airway mucosal edema, treats

Table 1: Causes of anaphylaxis during pregnancy.

\begin{tabular}{|c|}
\hline Non-Steroidal Anti-Inflammatory Medications \\
Intravenous Vitamins and Iron \\
Neuromuscular Blockers \\
\hline General Anesthetics \\
\hline Latex Products \\
\hline Antiseptic Agents e.g. Chlorhexidine \\
\hline
\end{tabular}

Table 2: Cases of anaphylaxis reported in second trimester and management and outcome.

\begin{tabular}{|c|c|c|c|c|c|}
\hline Author & Agent & $\begin{array}{l}\text { Gestational age at } \\
\text { anaphylaxis event } \\
\text { (weeks) }\end{array}$ & Management & $\begin{array}{l}\text { Maternal } \\
\text { Outcome }\end{array}$ & Neonatal Outcome \\
\hline Entman et al. (1984) [16] & $\begin{array}{l}\text { Snakebite } \\
\text { antivenin }\end{array}$ & 28 & $\begin{array}{l}\text { Ephinephrine, steroids, } \\
\text { isoproterenol, diphenhydramine }\end{array}$ & Good & Neurological damage \\
\hline Luciano et al. (1997) [17] & Iron & 27 & Not described & Good & Neurological damage \\
\hline Suri et al. (1999) [18] & Suxamethonium & 23 & Delivery at 35 weeks & Good & Neurologic damage \\
\hline Cole et al. (2000) [19] & Laminaria & 21 & $\begin{array}{c}\text { Antihistamines, steroids, } \\
\text { B-agonists }\end{array}$ & Good & $\begin{array}{l}\text { Death (elective } \\
\text { abortion) }\end{array}$ \\
\hline Vercauteren et al. (2003) [1] & Pentastarch & 28 & $\begin{array}{c}\text { Ephedrine, ranitidine, } \\
\text { promethazine, steroids, } \\
\text { aminophylline; Cesarean delivery } \\
\text { next day }\end{array}$ & Good & Good \\
\hline Biermann et al. (2005) [20] & Suxamethonium & 26 & Not described & Not described & Not described \\
\hline Berenguer et al. (2013) [15] & Amoxicillin & 28 & $\begin{array}{l}\text { Fluids, steroids antihistamines } \\
\text { indomethacin, magnesium \& pre- } \\
\text { term delivery }\end{array}$ & Good & $\begin{array}{l}\text { Neurologic damage } \\
\text { followed by death day } \\
\text { of life } 11\end{array}$ \\
\hline Truong et al. (2015)21 & Suxamethonium & 19 & Epinephrine & Good & Death \\
\hline Tsuzuki et al. (2017) [2] & $\begin{array}{l}\text { Food Allergy } \\
\text { (Soba noodles) }\end{array}$ & 25 & $\begin{array}{l}\text { Fluids, Epinephrine, } \\
\text { Antihistamine, Steroid }\end{array}$ & Good & $\begin{array}{l}\text { Good (no neurologic } \\
\text { deficiency) }\end{array}$ \\
\hline
\end{tabular}




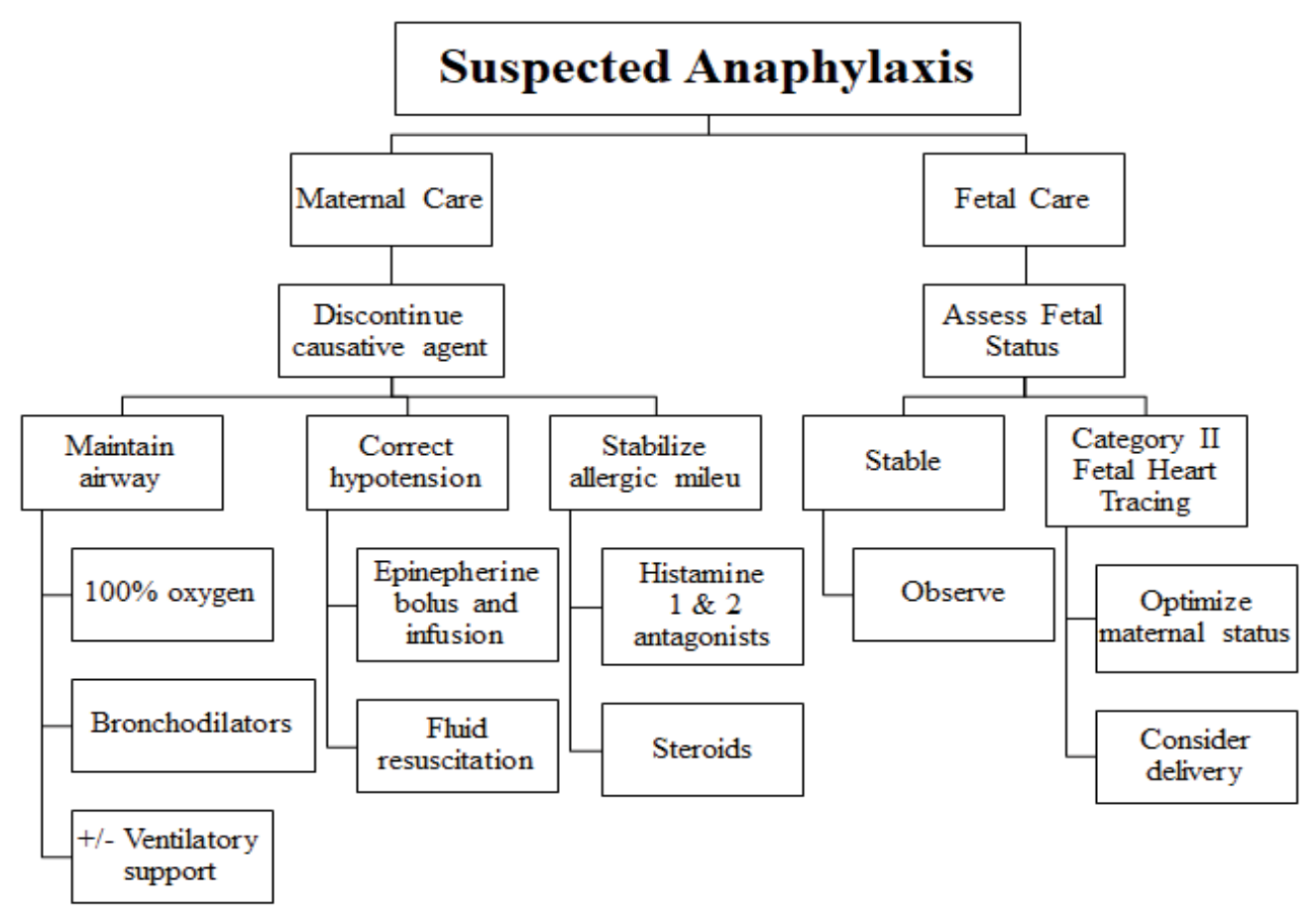

Figure 1 Steps in responding to anaphylaxis in pregnant patients at viable gestational ages.

hypotension, provides cardiac inotropic as well as chronotropic support and suppresses further mediator release from mast cells and basophils [5]. Advanced cardiac life support should be performed if indicated regardless of pregnancy status. In contrast to non-pregnant patients, left uterine displacement is required during resuscitation or the patient should be in left tilt position to remove aortocaval compression. Endotracheal intubation may be challenging in the setting of pregnancy due to associated edema of the upper airway, tongue swelling and obscured landmarks.

At the time of allergic reaction, the American Academy of Allergy, Asthma, and Immunology recommends collection of serum tryptase levels, plasma histamine, 24-hour urinary histamine metabolites, or urinary prostaglandin to assist in establishing a diagnosis of anaphylaxis [6]. Tryptase has a $72 \%$ sensitivity and $72 \%$ specificity, but mast cell tryptase value alone cannot be used to establish the diagnosis of anaphylaxis [7]. In our case, the tryptase value was not positive - likely because the blood sample was not sent to the lab on ice and may not have been processed properly. For women who report an allergy history, the American College of Obstetricians and Gynecologists now supports penicillin allergy skin testing in pregnancy [8].

Appropriate antibiotic prophylaxis against surgical site infection is imperative. Antibiotic stewardship will help prevent the increased side effects, poor bacterial coverage, and increased bacterial resistance to antibiotics due to alternative antibiotic choices. Suboptimal antibiotic choice due to incompletely investigated or inappropriately documented or allergies is causing an increase in maternal infection on a population level. It behooves providers to delineate true allergies and make plans for testing as necessary and plan for appropriate second line antibiotics.
The overall prevalence of anaphylactic reaction to cephalosporin is around $0.1 \%$ to $0.0001 \%$ [9]. Initial studies of cross reactivity between penicillin and cephalosporins is suggested to be as high as $10 \%$, but these studies were performed with early cephalosporins possibly with trace amounts of penicillin $[10,11]$. While penicillin and cephalosporin share a beta-lactam ring, cross reactivity is primarily determined by $\mathrm{R} 1$ side chain that is attached to the beta-lactam ring. There is no cross-reactivity between penicillin and cefazolin as they do not share similar R side chains [12]. Therefore, this patient could safely receive penicillin if needed without skin testing. If this patient were to need a cesarean delivery, cefazolin could be substituted by another first-generation cephalosporin with dissimilar $\mathrm{R}$ side chains to cefazolin, preventing cross reactivity while maintaining optimal surgical site infection prophylaxis [13]. Ceftezole is the only firstgeneration cephalosporin with similar $\mathrm{R}$ side chain to cefazolin and should therefore be avoid in this patient. Additionally, gentamycin with clindamycin would also be appropriate antibiotics for cesarean delivery [14]. Inappropriate alternative antibiotics are clindamycin only, gentamicin only, vancomycin or ampicillin only. Clindamycin has poor gram-negative coverage and can contribute to Clostridium difficile infection. Vancomycin can cause infusion-related red man syndrome and it has poor coverage of MSSA. Anesthesiologists play an important role in allergy assessment and management during the perioperative period and should be mindful of antibiotic stewardship and optimal antimicrobial coverage.

The importance of treating allergic reactions with epinephrine 
and close maternal fetal monitoring is demonstrated by the adverse outcome in a case of a pregnant woman with anaphylaxis to amoxicillin in the second trimester. She was treated with steroids and antihistamines, but not with epinephrine. Days later she delivered a severely neurologically impaired neonate who ultimately died [15-21]. Our emphasis on treating with epinephrine and maintaining maternal blood pressure and

\section{References}

1 Vercauteren MP, Coppejans HC, Sermeus L (2003) Anaphylactoid reaction to hydroxyethylstarch during cesarean delivery in a patient with HELLP syndrome. Anesth Analg 96: 859-861

2 Tsuzuki Y, Narita M, Nawa M, Nakagawa U, Wakai T (2017) Management of maternal anaphylaxis in pregnancy: A case report. Acute Med Surg 4: 202-204.

3 Chaudhuri K, Gonzales J, Jesurun CA, Ambat MT, Mandal-Chaudhuri $S$ (2008) Anaphylactic shock in pregnancy: A case study and review of the literature. Int J Obstet Anesth 17: 350-357.

4 Sheikh J (2007) Intrapartum anaphylaxis to penicillin in a woman with rheumatoid arthritis who had no prior penicillin allergy. Ann Allergy Asthma Immunol 99: 287-289.

5 Simons FE, Ardusso LR, Bilo MB (2011) World allergy organization guidelines for the assessment and management of anaphylaxis. World Allergy Organ J 4: 13-37.

6 Lieberman P, Camargo CA Jr, Bohlke K (2006) Epidemiology of anaphylaxis: findings of the American College of Allergy, Asthma and Immunology Epidemiology of Anaphylaxis Working Group. Ann Allergy Asthma Immunol 97: 596-602.

7 Francis A, Fatovich DM, Arendts G (2018) Serum mast cell tryptase measurements: Sensitivity and specificity for a diagnosis of anaphylaxis in emergency department patients with shock or hypoxaemia. Emerg Med Australas 30: 366-374.

8 ACOG Committee (2019) Prevention of Group B Streptococcal EarlyOnset Disease in Newborns: ACOG Committee Opinion Summary, Number 782. Obstet Gynecol 134: 206-210.

9 Vorobeichik L, Weber EA, Tarshis J (2018) Misconceptions Surrounding Penicillin Allergy: Implications for Anesthesiologists. Anesth Analg 127: 642-649. preventing maternal hypotension likely assisted in our good fetal outcome.

\section{Conclusion}

Prompt recognition and treatment of anaphylaxis resulted in complete resolution of anaphylaxis. Although uncommon, when anaphylaxis occurs during pregnancy prompt recognition and treatment is required to prevent maternal and fetal morbidity.

10 Romano A, Gueant-Rodriguez RM, Viola M (2005) Diagnosing immediate reactions to cephalosporins. Clin Exp Allergy 35: 12341242.

11 Kelkar PS, Li JT (2001) Cephalosporin allergy. N Engl J Med 345: 804809.

12 Romano A, Gueant-Rodriguez RM, Viola M, Pettinato R, Gueant JL (2004) Cross-reactivity and tolerability of cephalosporins in patients with immediate hypersensitivity to penicillins. Ann Intern Med 141: 16-22.

13 Zagursky RJ, Pichichero ME (2018) Cross-reactivity in beta-Lactam Allergy. J Allergy Clin Immunol Pract 6: 72-81 e1.

14 Kawakita T, Huang CC, Landy HJ (2018) Choice of Prophylactic Antibiotics and Surgical Site Infections After Cesarean Delivery. Obstet Gynecol 132: 948-955.

15 Berenguer A, Couto A, Brites V, Fernandes R (2013) Anaphylaxis in pregnancy: a rare cause of neonatal mortality. BMJ Case Rep.

16 Entman SS, Moise KJ (1984) Anaphylaxis in pregnancy. South Med J 77: 402 .

17 Luciano R, Zuppa AA, Maragliano G, Gallini F, Tortorolo G (1997) Fetal encephalopathy after maternal anaphylaxis: Case report. Biol Neonate 71: 190-193.

18 Suri S, Salfield S, Baxter P (1999) Congenital paraplegia following maternal hypotension. Dev Med Child Neurol 41: 273-274.

19 Cole DS, Bruck LR (2000) Anaphylaxis after laminaria insertion. Obstet Gynecol 95: 1025.

20 Biermann C, Tosin S, Bayoumeu F, Savoye E, Bouaziz H (2005) Anaphylactic shock and uterine atony: must we use sulprostone. Ann Fr Anesth Reanim 24: 69-70.

21 Truong HT, Browning RM (2015) Anaphylaxis-induced hyperfibrinolysis in pregnancy. Int J Obstet Anesth 24: 180-184 